\title{
C) MitcatóróRICA
}

O racismo estrutural no Brasil: desafios para o pensamento e atitudes antirracistas

\author{
ALMEIDA, Silvio Luiz de. Racismo estrutural. - São Paulo: Sueli Carneiro; Editora \\ Jandaíra, 2020, 264p. (Feminismos Plurais/coordenação de Djamila Ribeiro)
}

Ricardo Alves da S. Santos*

Frente a uma realidade em que a maioria da população brasileira se constitui de cor preta e parda, o racismo ainda impera definindo os lugares sociais da população não branca. É inevitável supor que os séculos de escravização de africanos e seus descendentes tenha gerado uma eficiente estrutura social de exclusão. Nas últimas décadas, tem ganhado espaço o debate em torno do racismo e suas consequências para o meio social. Nesse interim, a produção de autores negros vem contribuindo para legitimar as abordagens que confirmam a vitalidade do racismo no Brasil.

Silvio Almeida, um homem negro que percebeu ao longo de sua vida as exceções dadas aos de sua cor, soube indagar e perceber o racismo mesmo em suas formas mais sutis. De formação jurídica e filosófica, trouxe para seu livro Racismo estrutural análises balizadas no Direito, na Filosofia, na Economia e na Ciência Política, sem contudo abandonar a Sociologia e a História. Essas duas última tem em grande medida, conduzido o debate em torno da questão racial desde o fim da escravidão. E ao enveredar pela teoria social, Almeida nos apresenta os diversos entremeios em que o racismo se instalou para compor um racismo estrutural no Brasil.

Organizada em cinco capítulos, a obra objetiva defender duas teses: a primeira é que "a sociedade contemporânea não pode ser compreendida sem os conceitos de raça e de racismo" e a segunda é que "o significado de raça e de racismo, bem como suas terríveis consequências, exigem dos pesquisadores e pesquisadoras um sólido conhecimento da teoria social" (p. 20). Ao propor que "o racismo é sempre estrutural" quer dizer que como elemento que se manifesta como a normalidade numa sociedade, está presente na organização econômica e política. Dessa forma, o racismo dá sentido, lógica e tecnologia para a reprodução de mecanismos de desigualdade na vida social contemporânea.

"Doutorando em História pelo PGH/UFRPE, linha de pesquisa: Estado, sociedade e cultura. E-mail: riko.alves28@gmail.com 


\section{C) Hitsistórica}

No primeiro capítulo, Raça e racismo, o autor destaca a importância de compreender o significado de "raça" e coloca que não é um termo estagnado, mas dinâmico, cujo "sentido está inevitavelmente atrelado às circunstâncias históricas". Assim, vemos que "a história da construção política e econômica das sociedades contemporâneas" está diretamente relacionada com a história da raça (p. 24). Parte daí para dizer que antes de se consolidar enquanto estrutura, o racismo se fez nas instituições. "No caso do racismo institucional, o domínio se dá com o estabelecimento de parâmetros discriminatórios baseados na raça, que servem para manter a hegemonia do grupo racial no poder" (p. 40). É nesse contexto em que as instituições brasileiras, públicas e privadas, são dominadas por homens brancos como consequência "da existência de regras e padrões que direta ou indiretamente dificultam a ascensão de negros e/ou mulheres".

Almeida entende que as instituições dão consistência a uma estrutura social "que tem o racismo como um de seus componentes orgânicos" (p. 47) e que o racismo nas instituições ocorre porque tem por base uma sociedade racista. Desse modo, a escravidão no Brasil somente foi possível porque estava apoiada nas instituições e firmada numa sociedade que aceitava e apoiava tal prática. Foi a naturalização da escravização negra que permitiu sua longevidade, o que legou um racismo estrutural para a atualidade. Almeida enfatiza que “do ponto de vista teórico é que o racismo, como processo histórico e político, cria as condições sociais para que, direta ou indiretamente, grupos racialmente identificados sejam discriminados de forma sistemática" (p. 5I). Ao entender que o racismo é estrutural e que pessoas e instituições são condicionadas por essa estrutura, isso não retira a responsabilidade individual sobre a prática de condutas racistas, destaca o autor.

Sendo o racismo estrutural é também um processo político no sentido de que "como processo sistêmico de discriminação que influencia a organização da sociedade, depende do poder político" (p. 52-3). E enquanto processo histórico, entende-se que "a especialidade da dinâmica estrutural do racismo está ligada às particularidades de cada formação social” (p. 55). Assim, a formação histórica da formação social brasileira teve por base a escravidão negra africana e no processo de deslegitimação e extinção do escravismo, "as classificações raciais tiveram papel importante para definir as hierarquias sociais, a legitimidade do poder estatal e as estratégias econômicas de desenvolvimento" (p. 56). Dessa consideração torna-se evidente que no Brasil a Abolição da escravatura levou a uma reestruturação da sociedade e teve a "raça" como um novo classificador social. 


\section{C) Gitistór RICA}

No capítulo Ideologia e racismo o autor propõe que as pessoas em sua maioria (mesmo as que se declaram negras) com frequência, caem na armadilha de ao ver uma pessoa negra, imediatamente a associa a uma atividade subalterna, o que pode ser explicado pela realidade em que a maioria de homens e mulheres negros estão alocados em atividades pouco remuneradas e também por causa de um processo ideológico que "naturalizou" a interiorização dos afrodescendentes pois "o racismo como ideologia molda o inconsciente" e dessa forma "os padrões de clivagem racial inseridos no imaginário e em práticas sociais cotidianas" são percebidos e naturalizados na vida cultural e política dos indivíduos (p. 64). Portanto, "o racismo constitui todo um complexo imaginário social que a todo momento é reforçado pelos meios de comunicação, pela indústria cultural e pelo sistema educacional" (p. 65). E para que o racismo enquanto ideologia seja eficiente tem de estar "ancorado em práticas sociais concretas”.

A discriminação no imaginário social foi gestada e naturalizada por meio das manifestações culturais, em particular da cultura popular, mas também a ciência colaborou para naturalizar a discriminação, pois "a ciência tem o poder de produzir um discurso de autoridade, que poucas pessoas têm a condição de contestar" (p. 70). E assim vemos que no final do século XIX já se observava o crescimento de uma ciência racista fundada na esteira do darwinismo social e no evolucionismo e que no início do século XX, no contexto do Estado Novo, "o discurso socioantropológico da democracia racial brasileira seria parte relevante desse quadro em que cultura popular e ciência fundem-se num sistema de ideias que fornece um sentido amplo para práticas racistas já presentes na vida cotidiana” (p. 7I).

No tempo da escravidão, ser negro era sinônimo de escravo. Não importava a condição social, a cor da pele sempre seria um marcador social, situação que se perpetuou no pós-abolição. Agora que legalmente a escravidão fora extinta, a cor negra passa a ser um marcador de exclusão, de pobreza. Estando, pois, a cor negra associada à pobreza, a depender das condições econômicas favoráveis pode fazer de uma pessoa negra, branco. "Assim como o privilégio faz de alguém branco, são as desvantagens sociais e as circunstâncias histórico culturais, e não somente a cor da pele ou o formato do rosto, que fazem de alguém negro" (p. 77). No lado oposto, Almeida observa que "o pavor de um dia ser igualado a um negro é o verdadeiro fardo que carrega o homem branco da periferia do capitalismo e um dos fatores que garante a dominação política, econômica e cultural dos países centrais" (p. 79). Se até o século XIX a pele negra era associada à escravidão, hoje a condição de pobreza a que se encontram tanto os africanos como os afrodescendentes no 


\section{C) GițTó}

Brasil, favorece o imaginário social em que pessoas negras serão sempre vistas como subalternos.

Em Racismo e política, terceiro capítulo da obra, o autor evidencia que o Estado enquanto forma política do mundo na contemporaneidade, alimenta e reproduz o racismo por meio das estruturas estatais. Almeida entende que essas estruturas alimentam e reproduzem o racismo atuando na classificação e divisão das pessoas e grupos no sentido de dar sustentação aos grupos no poder. Aponta como exemplo explícito desse sistema o regime do apartheid na África do Sul. Também nos Estados Unidos, até a década de 1960, uma política de segregação cumpria a função de legitimar o poder dos brancos. Mas de forma velada, como no Brasil, o Estado incentiva e perpetua o racismo.

Ao se apresentar como o detentor e organizador da sociedade pelo princípio da lei e da razão pública, o Estado dilui e dispersa a ideia de raça e racismo, vistos "como uma irracionalidade em contraposição à racionalidade do Estado" (p. 89). Nesse sentido em que o Estado exerce domínio sobre o racismo, o autor adentra na seara do capitalismo para justificar o poder do Estado nas questões raciais. Para Almeida, "está longe de ser o Estado o resultado de um contrato social, a corporificação da vontade popular democrática, o ápice da racionalidade ou instrumento de opressão da classe dominante" (p. 9I). Vê dessa forma o Estado moderno por um ângulo mais complexo em que reflete uma organização social e política a partir das configurações do capitalismo. E explica que "a sociedade capitalista tem como característica fundamental a troca mercantil. Desse modo, a existência da sociedade capitalista depende que os indivíduos que nela vivem relacionem-se entre si, predominantemente, como livres e iguais" (p. 92).

Aqui caberia uma discussão mais aprofundada sobre a relação do sistema capitalista e uma sociedade em que predomine a liberdade e a igualdade de seus indivíduos. Ao definir que o capitalismo como condição para existir tinha que o Estado "assegurar o direito à liberdade individual", considero essa ideia problemática. Se olharmos para o Brasil do século XIX, vemos a consolidação do capitalismo diante do cenário de escravidão, ou seja, o capitalismo aqui não necessitou da liberdade dos indivíduos e nem o Estado garantiu isso, ao contrário, atuou para a manutenção da escravidão ao mesmo tempo em que ampliava a produção do café. Dale Tomich em Pelo prisma da escravidão (20II) evidencia esse processo de ampliação da escravidão para atender as demandas de produção do algodão no sul dos Estados Unidos, do açúcar em Cuba e do café no Brasil, ao que denominou de segunda 


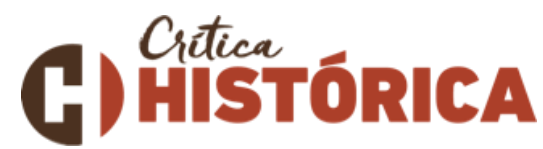

escravidão essa relação de crescimento da escravidão na esteira do capitalismo nas primeiras décadas do XIX.

Dadas as circunstancias acima, o capitalismo não necessariamente se faria sob a prerrogativa da liberdade. Assim, ao Estado caberia "a manutenção da ordem - garantia da liberdade e da igualdade formais e proteção da propriedade privada e do cumprimento dos contratos" (p. 93). Dessa forma, com o fim da escravidão, perpetuou-se o ideário do ordenamento da população de cor e mesmo sob um novo regime político - a República - a liberdade e a igualdade se fizeram de forma legal, mas não na prática. O racismo continuou a segregar a sociedade brasileira, pois "sob as condições econômicas da sociedade capitalista, o Estado dá forma a uma comunidade política cuja socialização é feita de antagonismos e contradições expressas nos interesses individuais" (p. 94). Predominantes na organização e funcionamento das estruturas estatais, os homens brancos (herdeiros dos antigos senhores escravistas), detentores de capitais, tendem a impor sua ideologia na sociedade por meio do Estado.

Em Racismo e direito, Almeida se detém a explicar o que é de fato o "direito". Para ele, as normas estatais (leis, códigos, decretos e resoluções) seriam a expressão do que chamamos de direito que vem a ser a manifestação da vontade e do poder dos que detém o controle estatal e "sem o poder as normas jurídicas não passariam de abstrações sem realidade" (p. 134). Para que essas normas sejam cumpridas deve vir acompanhada da vigilância e opressão. Nessa condição, o direito atua como instrumento de controle social. Se o grupo que está no poder é racista, as normas jurídicas refletem "os projetos de discriminação sistemática, segregação racial e até de extermínio" (p. 136). O nazismo e o apartheid são exemplos de como o direito está a serviço dos que detém o poder, legitimando suas ações. A escravidão no Brasil também teve seu amparo jurídico e o seu fim somente foi possível graças a uma lei que redefiniu a escravidão como ilegal.

No quinto e último capítulo, Racismo e economia, o autor propõe compreender o racismo pelo viés da desigualdade. Em sua análise, demonstra "que a raça é um marcador determinante da desigualdade econômica" (p. I56). Isso é demonstrado pela realidade em que vemos pessoas negras e mulheres, exercendo trabalhos de baixa remuneração e considerados precários. O capítulo traz diversos teóricos que se debruçaram a explicar a desigualdade a partir da teoria econômica e assim oferecem "importantes contribuições que se ampararam em uma perspectiva estrutural, a qual obriga a economia a voltar-se novamente para a sua dimensão política" (p. I67). Estando a economia ligada à política, a 


\section{C) HistótórRICA}

estrutura institucional é relevante para compreender e oferecer soluções para os problemas da sociedade. Educação, saúde, saneamento básico e renda, são alguns temas presentes nessa relação.

A força econômica capitalista, para dar funcionamento às condições subjetivas para que os indivíduos naturalizem e vivenciem a troca mercantil, reproduz e reforça preconceitos e ações discriminatórias. A meritocracia é um bom exemplo dessa subjetividade capitalista ao ver a condição de pobreza dos negros como o resultado da sua incapacidade ou inércia no mercado competitivo, desprezando as condições históricas e estruturais. O racismo por sua vez é sufocado, invisibilizado. Mas isso não ocorre ao acaso ou de forma espontânea, "os sistemas de educação e meios de comunicação de massa são aparelhos que produzem subjetividades culturalmente adaptadas em seu interior" (ALMEIDA, 2020, p. I69). Por isso, somente com muita atenção e vontade é possível enxergar que os trabalhos precários são exercidos em sua maioria por pessoas negras; que os negros são maioria no sistema carcerário, nas periferias, nos subempregos etc. É o negro o alvo principal dos órgãos de repressão e do abandono das autoridades.

O livro em si é uma ótima reflexão sobre os variados meios de funcionamento do racismo, seja nas instituições, nas ideologias, na política, no direito e na economia, o que compõe uma estrutura discriminatória eficiente porque não é explicitado, mas que é naturalizado e, portanto, difícil de ser rompido. Deixa evidente que no Brasil e nos demais países de passado colonial, o racismo é um resquício da escravidão. E apesar de haver hoje uma crescente valorização da cultura afro-brasileira e da diversidade racial e cultural no Brasil é preciso enfatizar que "diversidade não basta, é preciso igualdade".

Recebido em: I4 de maio de 202I.

Aprovado em: 2I de junho de 202I. 